\title{
Overexpression of Stathmin 1 correlates with poor prognosis and promotes cell migration and proliferation in oesophageal squamous cell carcinoma
}

\author{
PENG-ZHI NI ${ }^{1 *}$, JIAN-ZHONG HE ${ }^{2,3^{*}}$, ZHI-YONG WU ${ }^{5 *}$, XIANG JI $^{1}$, LONG-QI CHEN ${ }^{1}$, XIU-E XU ${ }^{2,3}$, \\ LIAN-DI LIAO ${ }^{2,3}$, JIAN-YI WU ${ }^{2,5}$, EN-MIN LI ${ }^{2,4}$ and LI-YAN XU ${ }^{2,3}$ \\ ${ }^{1}$ Department of Thoracic Surgery, West China Hospital of Sichuan University, Chengdu, Sichuan 610041; \\ ${ }^{2}$ The Key Laboratory of Molecular Biology for High Cancer Incidence Coastal Chaoshan Area, \\ ${ }^{3}$ Institute of Oncologic Pathology and ${ }^{4}$ Department of Biochemistry and Molecular Biology, \\ Shantou University Medical College, Shantou, Guangdong 515041; ${ }^{5}$ Department of Oncology Surgery, \\ Shantou Central Hospital, Affiliated Shantou Hospital of Sun Yat-Sen University, Shantou, Guangdong 515041, P.R. China
}

Received April 4, 2017; Accepted September 21, 2017

DOI: $10.3892 / o r .2017 .6039$

\begin{abstract}
Stathmin 1 (STMN1) is a microtubule-regulated protein that plays an important role in tumour cell proliferation and migration. Overexpression of STMN1 is associated with clinicopathological characteristics in many human cancers. The aim of the present study was to investigate STMN1 expression, its correlation with clinicopathological characteristics, and its exact biological function in oesophageal squamous cell carcinoma (ESCC). STMN1 levels were measured in the ESCC tissue specimens of 276 patients by immunohistochemistry (IHC) to assess the prognostic efficacy of STMN1. IHC showed that patients with overexpression of STMN1 had a poorer prognosis compared with those with low expression, both in regards to 5-year overall survival (OS; 21.2 vs. $53.7 \%, \mathrm{P}<0.001$ ) and disease-free survival (DFS; 20.6 vs. $50.9 \%, \mathrm{P}<0.001)$. STMN1 overexpression was associated with lower cell differentiation in tumour grade (correlation coefficient: $0.127, \mathrm{P}=0.037$ ). In multivariate analysis, STMN1 expression was found to be an independent prognostic factor for both OS ( $\mathrm{P}<0.001 ; 95 \% \mathrm{CI}, 1.555-2.970)$ and $\mathrm{DFS}(\mathrm{P}=0.001$; 95\% CI, 1.978-2.444). Compared with the control, STMN1 downregulation significantly decreased cell migration, invasion
\end{abstract}

Correspondence to: Professor Long-Qi Chen, Department of Thoracic Surgery, West China Hospital of Sichuan University, 37 Guoxue Alley, Chengdu, Sichuan 610041, P.R. China

E-mail: drchenlq@scu.edu.cn

Professor Li-Yan Xu, The Key Laboratory of Molecular Biology for High Cancer Incidence Coastal Chaoshan Area, Shantou University Medical College, Shantou, Guangdong 515041, P.R. China

E-mail:1yxu@stu.edu.cn

*Contributed equally

Key words: STMN1, prognosis, migration, invasion, proliferation, oesophageal squamous cell carcinoma and proliferation, whereas these were increased by STMN1 upregulation. STMN1 expression was significantly associated with prognosis and tumour differentiation in ESCC, indicating that STMN1 expression is an independent prognostic factor for ESCC and could be a potential biomarker. Regulating the expression of STMN1 could influence tumour cell motility, invasion and proliferation.

\section{Introduction}

Oesophageal carcinoma (EC) is one of the most common and aggressive cancers, and the sixth leading cause of cancer-related death worldwide, particularly in Africa and Asia $(1,2)$. Oesophageal squamous cell carcinoma (ESCC) is the predominant histological subtype in China. Even with the development of treatment strategies, surgical techniques and perioperative nursing, the overall survival (OS) of EC patients remains at $15-25 \%$ (3). Therefore, identification of key prognostic biomarkers and effective therapeutic targets is important for the current clinical management of ESCC. In the present study, we explored the clinical significance and the function of STMN1 in tumour cells of ESCC.

Stathmin 1 (STMN1), also known as p17, p18, p19, 19K, metablastin, oncoprotein 18 and LAP 18, is a microtubuleregulated protein that plays an important role in the disassembly of the mitotic spindle and cell cycle progression. STMN1 is activated by dephosphorylation and binds two $\alpha$ - and $\beta$-tubulin heterodimers during the process of microtubule disassembly (4). Furthermore, STMN1 also has been found to affect cell proliferation, differentiation, migration and signal transduction. The dysfunction of STMN1, resulting in consistent microtubule assembly, cell cycle disorder, microtubule dynamic destabilization and abnormal signal transduction, is closely related to tumour metastasis $(4,5)$. STMN1 is highly expressed in many malignancies including acute leukaemia (6), lymphoma (7), ovarian carcinoma (8), prostate (9), breast (10) and head and neck cancer (11), hepatocellular carcinoma (12), osteosarcoma (13), lung cancer $(14,15)$ and mesothelioma (7). 
These findings indicate that STMN1 is closely related to human cancers and an important biomarker for diagnosis and prognosis. Overexpressed STMN1 was found to be associated with lymph node metastasis, poor prognosis and recurrence in ESCC $(16,17)$. However, the correlation between STMN1 expression and clinicopathological characteristics, prognosis and biological function of STMN1 in ESCC remains largely unclear. The aim of the present study was to identify the expression and investigate the biological function of STMN1 in ESCC.

\section{Materials and methods}

Patients and specimens. Tissue specimens from 276 patients who underwent surgical resection were collected between November 2007 and January 2010 at The Shantou Central Hospital. None of them had distant metastasis. All tumours were confirmed by pathologists as ESCC staged according to the 7th Edition of the American Joint Committee on Cancer (AJCC) Tumor-Node-Metastasis (TNM) Staging System for ESCC (18). Tumour grade was defined as well differentiated, moderately differentiated or poorly differentiated, according to the World Health Organization (WHO) classification of oesophageal tumours (19). The main clinicopathological characteristics of the patients are summarised in Table I. OS was defined as the interval between surgery and death from the tumour or between surgery and the last observation taken for surviving patients. Disease-free survival (DFS) was defined as the interval between surgery and the diagnosis of relapse or death. Ethical approval was obtained from the Ethics Committees of the Central Hospital of Shantou City, the Medical College of Shantou University and the West China Hospital. Only resected samples from surgical patients giving written informed consent were included for use in the research.

Cell culture. ESCC cell lines (KYSE150 and KYSE450) were generous gifts from Professor Ming-Zhou Guo, Department of Gastroenterology and Hepatology, Chinese PLA General Hospital. KYSE150 cells were cultured in RPMI-1640 medium (Thermo Fisher Scientific Inc., Waltham, MA, USA) with 10\% foetal bovine serum (Gibco, Grand Island, NY, USA) and KYSE450 cells were cultured in Dulbecco's modified Eagle's medium (Thermo Fisher Scientific Inc.) with $10 \%$ foetal bovine serum. All cell lines were incubated at $37^{\circ} \mathrm{C}$ in a humidified atmosphere containing $5 \% \mathrm{CO}_{2}$.

Tissue microarrays (TMAs) and immunohistochemistry (IHC). TMAs were constructed based on standard techniques and IHC was carried out using a two-step protocol (PV-9000 Polymer Detection System; ZSGB-BIO, Beijing, China) according to the manufacturer's instructions. These techniques were previously described $(20,21)$.

All sections were analysed blindly by two experienced pathologists. Each separate tissue core was scored on the basis of the intensity and positive staining proportion according to the literature (22). The intensity of positive staining was scored as follows: 0, negative; 1 , weak; 2, moderate; and 3, strong. The proportion of positive cells was scored on a $0-4$ scale as follows: $0,0-5 \% ; 1,6-25 \% ; 2,26-50 \% ; 3,51-75 \%$ and $4,>75 \%$. If the positive staining was homogeneous, a final score was achieved by multiplication of the two scores, producing a total range of $0-12$. When the staining was heterogeneous, each component was independently scored and summed for the results. The mean value of the two scores was considered representative of one tumour. For statistical analysis, X-Tile software was used to separate the STMN1 expression score into two subgroups: high expression and low expression.

siRNA transfection. Double-stranded small interfering RNAs (siRNAs) were synthesised in duplex and purified forms by GenePharma Co. (Shanghai, China). Four sequences were designed and filtered out to select the one that was most interference efficient. The sequences were as follows: siRNA $1 \mathrm{~F}$, 5'-AGAAGAAGGAUCUUUCCCU-3' and R, 3'-AGGGAAA GAUCCUUCUUCU-5'; siRNA 2 F, 5'-AAUGGCAGAAG AGAAACUG-3' and R, 3'-CAGUUUCUCUUCUGCCAUU-5'; SiRNA 3 F, 5'-AAGAGUAUGUAGUGGCUUC-3' and R, 3'-GAAGCCACUACAUACUCUU-5'; siRNA 4 F, 5'-AAG CACAAGCGUGUUUCUA-3' and R, 3'-UAGAAACACG CUUGUGCUU-5'. STMN1 was silenced using Lipofectamine ${ }^{\circledR}$ RNAiMAX Transfection reagent (Invitrogen, Carlsbad, CA, USA) according to the manufacturer's protocol. The controls were treated with nonsense siRNA. After $48 \mathrm{~h}$, proteins were extracted and the interference efficiency was confirmed.

Plasmid transfection. The plasmids Flag-STMN1 were purchased from Sino Biological Inc. (Beijing, China). FlagSTMN1 was transiently transfected into KYSE150 and KYSE450 cells, using Lipofectamine ${ }^{\circledR} 3000$ transfection reagent (Invitrogen) according to the manufacturer's instructions.

Western blot analysis. Standard western blot analysis was performed as previously described (23). Briefly, proteins were separated by sodium dodecyl sulfate-polyacrylamide gel electrophoresis (SDS-PAGE) and transferred to polyvinylidene fluoride (PVDF) membranes (Millipore, Billerica, MA, USA). The membranes were blocked in 5\% non-fat milk for $1 \mathrm{~h}$, followed by the addition of anti-STMN1 (Santa Cruz Biotechnology, Santa Cruz, CA, USA) overnight at $4^{\circ} \mathrm{C}$. The membranes were then washed and incubated with secondary antibody coupled to horseradish peroxidase for $1 \mathrm{~h}$. Antigenantibody complexes were detected by Western Blotting Luminol reagent (Santa Cruz Biotechnology). Photography and quantitative analyses of related-immunoreactive bands were performed using a FluorChem ${ }^{\mathrm{TM}}$ IS-8900 (Alpha Innotech, San Leandro, CA, USA).

Wound healing assay. At $48 \mathrm{~h}$ after transfection, cells were spread in a layer and serum-starved for $12 \mathrm{~h}$ before wounding. A $1,000-\mu 1$ pipette tip was used to create a wound across the diameter of the well. Cell migration across the wound surface was then assessed by microscopy after every $24 \mathrm{~h}$. Images were captured under a magnification of x40 (DMI3000B; Leica, Wetzlar, Germany). Adobe Illustrator CS5 was used to measure the distance between the edges of the wound.

Cell migration and invasion assays. Cell invasion and migration assays were performed as described below. At $48 \mathrm{~h}$ after transfection with siSTMN1 or Flag-STMN1 or their corresponding negative control, cells were starved for $12 \mathrm{~h}$ and $6 \times 10^{5}$ starved cells were seeded into Transwells (BD Biosciences, San Jose, 
Table I. Correlation between STMN1 expression and clinicopathological characteristics in ESCC.

\begin{tabular}{|c|c|c|c|c|c|}
\hline \multirow{2}{*}{$\begin{array}{l}\text { Clinicopathological } \\
\text { characteristics }\end{array}$} & \multirow[b]{2}{*}{ No. of cases $(\%)$} & \multicolumn{2}{|c|}{ STMN1 expression } & \multicolumn{2}{|c|}{ Correlation analysis } \\
\hline & & Low, n (\%) & High, n (\%) & Corr. coefficient & P-value \\
\hline Sex & & & & -0.31 & 0.601 \\
\hline Female & $58(21.0)$ & $37(63.8)$ & $21(36.2)$ & & \\
\hline Male & $218(79.0)$ & $147(67.4)$ & $71(32.6)$ & & \\
\hline Age (years) & & & & 0.000 & 1.000 \\
\hline$\leq 55$ & $108(39.1)$ & $72(66.7)$ & $36(33.3)$ & & \\
\hline$>55$ & $168(60.9)$ & $112(66.7)$ & $56(33.3)$ & & \\
\hline Location & & & & -0.042 & 0.483 \\
\hline Upper & $17(6.2)$ & $10(58.8)$ & $7(41.2)$ & & \\
\hline Middle & $117(42.4)$ & $77(65.8)$ & $40(34.2)$ & & \\
\hline Lower & $142(51.4)$ & $97(68.3)$ & $45(31.7)$ & & \\
\hline Tumour size $^{\mathrm{a}}(\mathrm{cm})$ & & & & -0.054 & 0.347 \\
\hline$\leq 3$ & $62(22.6)$ & $38(61.3)$ & $24(38.7)$ & & \\
\hline $3-5$ & $131(47.8)$ & $88(67.2)$ & $43(32.8)$ & & \\
\hline$\geq 5$ & $81(29.6)$ & $56(69.1)$ & $25(30.9)$ & & \\
\hline Differentiation & & & & 0.127 & 0.037 \\
\hline $\mathrm{G} 1$ & $43(15.6)$ & $31(72.1)$ & $12(27.9)$ & & \\
\hline $\mathrm{G} 2$ & $212(76.8)$ & $145(68.4)$ & $67(31.6)$ & & \\
\hline G3 & $21(7.6)$ & $8(38.1)$ & $13(61.9)$ & & \\
\hline $\mathrm{pT}$ & & & & 0.033 & 0.561 \\
\hline $\mathrm{T} 1$ & $11(4.0)$ & $8(72.7)$ & $3(27.3)$ & & \\
\hline $\mathrm{T} 2$ & 43 (15.6) & $30(69.8)$ & $13(30.2)$ & & \\
\hline $\mathrm{T} 3$ & $221(80.1)$ & 145 (65.6) & $76(34.4)$ & & \\
\hline $\mathrm{T} 4 \mathrm{a}$ & $1(0.4)$ & $1(100)$ & 0 & & \\
\hline $\mathrm{pN}$ & & & & 0.087 & 0.124 \\
\hline No & 137 (49.6) & $97(70.8)$ & $40(29.2)$ & & \\
\hline $\mathrm{N} 1$ & $72(26.1)$ & $46(63.9)$ & $26(36.1)$ & & \\
\hline $\mathrm{N} 2$ & $50(18.1)$ & $32(64.0)$ & $18(36.0)$ & & \\
\hline N3 & $17(6.2)$ & $9(52.9)$ & $8(47.1)$ & & \\
\hline TNM stage & & & & 0.110 & 0.053 \\
\hline I & $22(8.0)$ & $18(81.8)$ & $4(18.2)$ & & \\
\hline II & $129(46.7)$ & $89(69.0)$ & $40(31.0)$ & & \\
\hline III & $125(45.3)$ & $77(61.6)$ & $48(38.4)$ & & \\
\hline Adjuvant therapy & & & & 0.070 & 0.223 \\
\hline No & $148(53.6)$ & $102(68.9)$ & $46(31.1)$ & & \\
\hline Radiotherapy & $41(14.9)$ & $27(65.9)$ & $14(34.1)$ & & \\
\hline Chemotherapy & $59(21.4)$ & $42(71.2)$ & $17(28.8)$ & & \\
\hline Radiochemotherapy & $28(10.1)$ & $13(46.4)$ & $15(53.6)$ & & \\
\hline
\end{tabular}

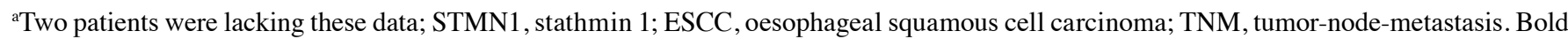
print (p-value) indicates a significant difference.

CA, USA) with $8-\mu \mathrm{m}$ pore size membranes coated with or without Matrigel (for invasion and migration assays, respectively). After $48 \mathrm{~h}$, cells within the Transwells were removed and migrated/invaded cells on the bottom of the Transwell were stained with crystal violet. Images of migrated/invaded cells on the Transwell membrane were captured under a magnification of $\mathrm{x} 200$, and the numbers of migratory/invaded cells were counted from at least 10 different fields.
Colony formation assay. Transfected cells were trypsinised, counted with a cell counter (Bio-Rad, Hercules, CA, USA), and then 1,000 cells (or 500 cells) were inoculated in each well of 6-well (or 12-well) plates. Cultures were maintained for two weeks, and cells were then fixed, stained and photographed.

Cell proliferation assay. The CellTiter $96{ }^{\circledR}$ AQueous One Solution Cell Proliferation Assay (MTS; Promega, Madison, 

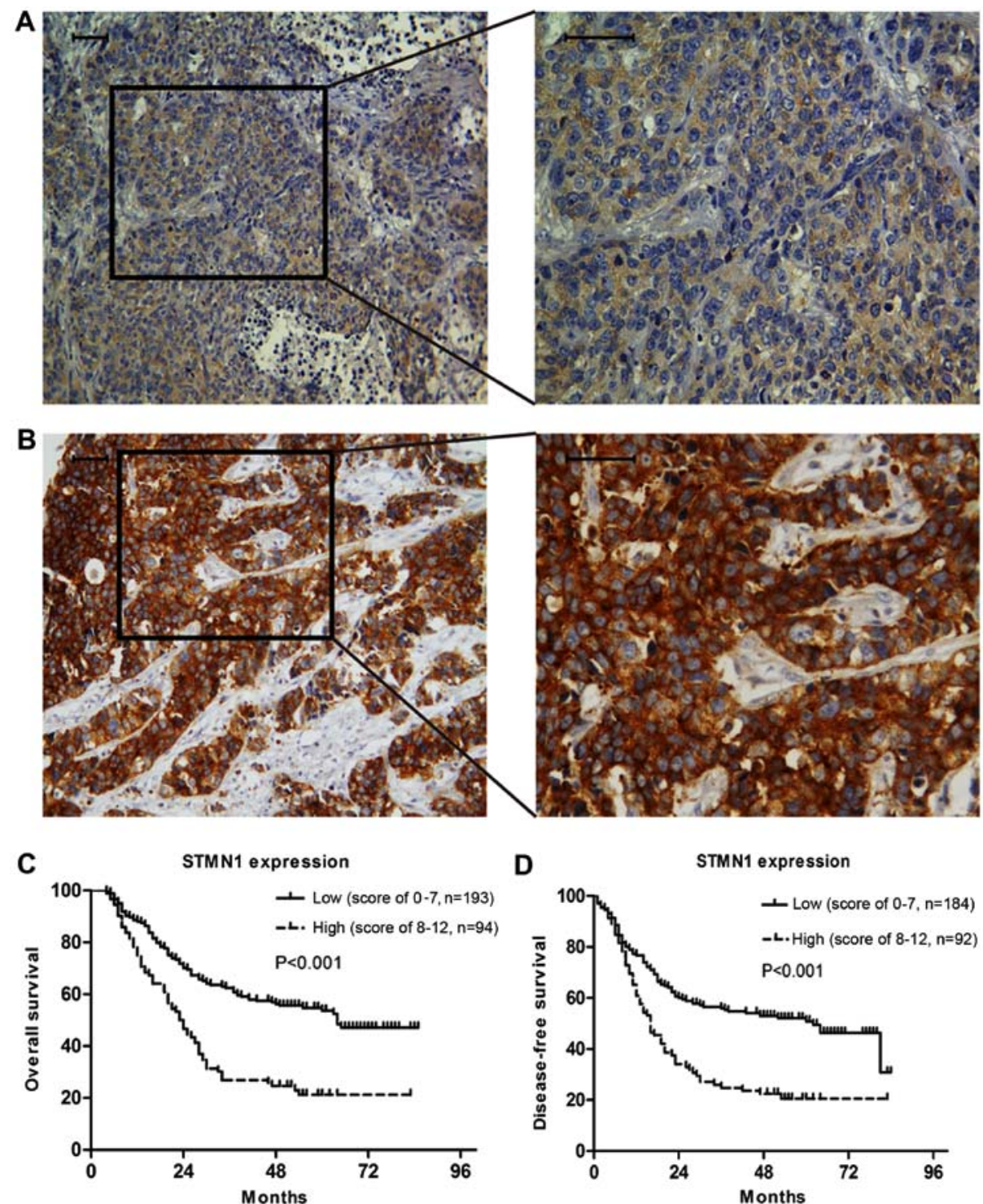

Figure 1. STMN1 expression in oesophageal squamous cell carcinoma (ESCC) by immunohistochemistry and the overall survival (OS) and disease-free survival (DFS) based on STMN1 expression in 276 ESCC patients. (A) Low expression of STMN1 in ESCC tissues. (B) High expression of STMN1 in ESCC tissues. (C) Overall survival of the ESCC patients according to STMN1 expression. (D) DFS of the ESCC patients according to STMN1 expression.

WI, USA) was used to measure cell proliferation. Cells that had been transfected for $48 \mathrm{~h}$ were seeded in a 96 -well plate. Every $24 \mathrm{~h}, 20 \mu \mathrm{l}$ of MTS reagent was added to the plate. After incubation at $37^{\circ} \mathrm{C}$ for $2 \mathrm{~h}$, the absorbance was measured at $492 \mathrm{~nm}$.

Cell cycle analysis. For cell cycle analysis by flow cytometry, transfected cells were fixed with $70 \%$ ethanol overnight at $4^{\circ} \mathrm{C}$. Cell pellets were incubated in phosphate-buffered saline (PBS) containing $0.1 \%$ Triton $\mathrm{X}-100$ for $10 \mathrm{~min}$ at room temperature, and then were treated with RNase $(50 \mathrm{mg} / \mathrm{ml})$ for $10 \mathrm{~min}$ and propidium iodide (PI; $5 \mathrm{mg} / \mathrm{ml}$ ) for $30 \mathrm{~min}$, respectively. FlowJo 7.6 software was used to determine the cell cycle phases.

Statistical analysis. Statistical analyses were performed using SPSS 19.0 software (SPSS, Inc., Chicago, IL, USA). Categorical data were compared using the Chi-square test or Fisher's exact probability test. Correlation analysis was performed using
Kendall's tau coefficient. Kaplan-Meier survival analyses were used to estimate 5-year OS and DFS in patients with ESCC. The log-rank test was used to assess differences in survival between groups. The Cox proportional hazard regression model was used to perform a multivariate analysis, and the risk ratio and its $95 \%$ confidence interval were recorded. A two-sided P-value $<0.05$ was considered to indicate a statistically significant result.

\section{Results}

Overexpression of STMN1 predicts a poorer prognosis in ESCC. The IHC staining showed that the expression of STMN1 in ESCC was mainly located in the cytoplasm (Fig. 1). The impact of STMN1 expression on the OS and DFS of ESCC patients was evaluated by Kaplan-Meier survival analysis. The median length of OS and DFS was 34.0 (range, 4-85) and 24 (range, 0-84) months, respectively. The IHC results of 276 patients showed that patients with high STMN1 expression (IHC score, 8-12) had a poorer prognosis compared with the patients with low 
A

B

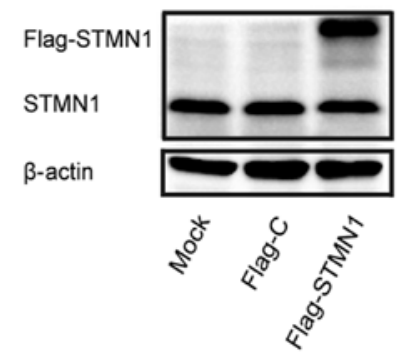

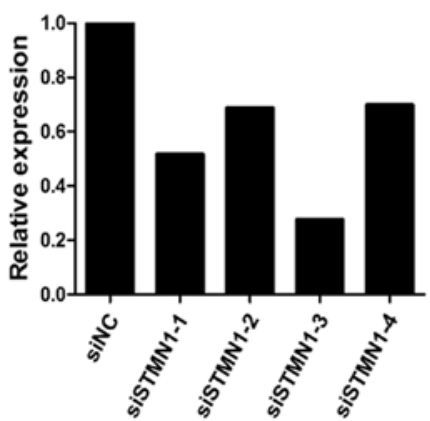

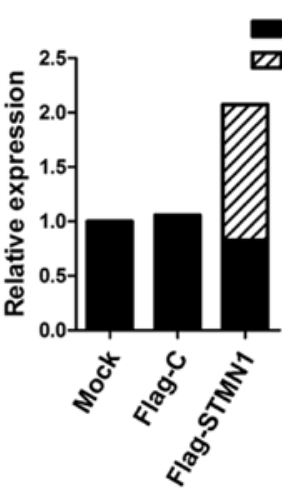

Figure 2. STMN1 expression in the KYSE150 cells following transfection with STMN1 siRNA and plasmids. (A) STMN1 expression following STMN1 siRNA transfection. (B) STMN1 expression following STMN1 plasmid transfection.

STMN1 expression (IHC score, 0-7). The 5-year OS rates of ESCC patients with high and low STMN1 expression were 21.2 and $53.7 \%(\mathrm{P}<0.001)$ (Fig. 1C), and the DFS rates were 20.6 and $50.9 \%(\mathrm{P}<0.001)$, respectively (Fig. 1D).

In addition, we performed univariate and multivariate analyses to investigate the prognostic factors for ESCC. We found that age $(\mathrm{P}=0.002 ; 95 \% \mathrm{CI}, 1.228-2.434)$, tumour length $(\mathrm{P}=0.046 ; 95 \% \mathrm{CI}, 1.004-1.560), \mathrm{pN}$ stage $(\mathrm{P}=0.005$; 95\% CI, 1.117-1.840) and STMN1 expression $(\mathrm{P}<0.001$; 95\% CI, 1.559-2.970) were independent prognostic factors for OS (Table II). Tumour length $(\mathrm{P}=0.010 ; 95 \% \mathrm{CI}, 1.072$ 1.678), $\mathrm{pN}$ stage $(\mathrm{P}=0.010 ; 95 \% \mathrm{CI}, 1.081-1.775)$ and STMN1 expression $(\mathrm{P}=0.001 ; 95 \% \mathrm{CI}, 1.278-2.444)$ were independent prognostic factors for DFS (Table III).

Correlation between STMN1 expression and clinicopathological characteristics in ESCC. We investigated the relationship between STMN1 expression and the clinicopathological characteristics of the ESCC patients. The results showed that STMN1 expression was found to be correlated with tumour grade (Table I). There were 12 patients $(27.9 \%)$ with high STMN1 expression out of 43 patients with tumours that were well differentiated, 67 patients $(31.6 \%)$ with high STMN1 expression out of 212 patients with tumours that were moderately differentiated, and 13 patients $(61.9 \%)$ with high STMN1 expression out of 21 patients with tumours that were poorly differentiated (correlation coefficient, 0.127, $\mathrm{P}=0.037$ ).

STMN1 expression following STMN1 siRNA and plasmid transfection. To explore the effect of STMN1 on ESCC, four siRNAs were designed to knock down STMN1 expression in KYSE150. The STMN1 expression was inhibited at the protein level up to $72.3 \%$ in the KYSE150 cells (siRNA-3) (Fig. 2A). Flag-STMN1 was also transfected to upregulate the STMN1 expression in KYSE150. The STMN1 expression was upregulated at the protein level by up to $200 \%$ in the KYSE150 cells (Fig. 2B).

Knockdown of STMN1 expression inhibits ESCC cell migration and invasion. Wound-healing assay was performed in both KYSE150 and KYSE450 cells. The results showed that cell migration was inhibited after the knockdown of STMN1 expression (Fig. 3A). Furthermore, migration and invasion assays were performed in Transwell chambers. The migration and invasion abilities were both inhibited after downregulation of STMN1 expression in the KYSE150 and KYSE450 cells (Fig. 3B).

Knockdown of STMN1 expression inhibits ESCC cell proliferation and induces cell cycle arrest in the G1 phase. Colony formation and cell proliferation assays were performed to investigate the influence of the knockdown of STMN1 expression on ESCC cells. The results showed that STMN1 downregulation significantly decreased the number of cell colonies (Fig. 4A). The same results were also seen in the proliferation assay by MTS in both the KYSE150 and KYSE450 cells (Fig. 4B).

Furthermore, a flow cytometric assay was performed to measure the function of STMN1 in cell cycle distribution. Upregulation of STMN1 expression induced cell cycle arrest in the G1 phase in the KYSE450 cells (Fig. 4C). In cells transfected with siSTMN1, the percentage of cells in the G1 phase was $65.9 \pm 4.6 \%$, which was significantly higher than that noted in the control cells $(46.8 \pm 2.2 \%)(\mathrm{P}<0.05)$. Moreover, the percentage of siSTMN1 cells in the $\mathrm{S}$ phase was 
Table II. Univariate and multivariate analyses of overall survival (OS) on clinicopathological characteristics.

\begin{tabular}{|c|c|c|c|c|c|c|}
\hline \multirow{2}{*}{$\begin{array}{l}\text { Patient } \\
\text { characteristics }\end{array}$} & \multirow{2}{*}{$\begin{array}{l}\text { No. of } \\
\text { patients }\end{array}$} & \multirow{2}{*}{$\begin{array}{c}\text { MST } \\
\text { (month) }\end{array}$} & \multirow{2}{*}{$\begin{array}{c}\begin{array}{c}\text { Univariate } \\
\text { analysis }\end{array} \\
\text { P-value }\end{array}$} & \multicolumn{3}{|c|}{ Multivariate analysis } \\
\hline & & & & HR & $95 \% \mathrm{CI}$ & P-value \\
\hline Gender & & & 0.599 & & & \\
\hline Male & 218 & 37.0 & & & & \\
\hline Female & 58 & 41.0 & & & & \\
\hline Age (years) & & & 0.019 & 1.729 & $1.228-2.434$ & 0.002 \\
\hline$\leq 55$ & 108 & 63.0 & & & & \\
\hline$>55$ & 168 & 30.0 & & & & \\
\hline Location & & & 0.492 & & & \\
\hline Ut & 17 & 24.0 & & & & \\
\hline Mt & 117 & 48.0 & & & & \\
\hline $\mathrm{Lt}$ & 142 & 37.0 & & & & \\
\hline Differentiation & & & 0.018 & 1.201 & $0.856-1.685$ & 0.290 \\
\hline G1 & 43 & 64.0 & & & & \\
\hline $\mathrm{G} 2$ & 212 & 35.0 & & & & \\
\hline $\mathrm{G} 3$ & 21 & 22.0 & & & & \\
\hline Length (cm) & & & 0.043 & 1.252 & $1.004-1.560$ & 0.046 \\
\hline$\leq 3$ & 62 & 65.0 & & & & \\
\hline $3-5$ & 131 & 34.0 & & & & \\
\hline$\geq 5$ & 81 & 30.0 & & & & \\
\hline pT & & & 0.169 & & & \\
\hline $\mathrm{T} 1$ & 11 & $55.3^{\mathrm{a}}$ & & & & \\
\hline $\mathrm{T} 2$ & 43 & 46.0 & & & & \\
\hline $\mathrm{T} 3$ & 221 & 34.0 & & & & \\
\hline $\mathrm{T} 4$ & 1 & 20.0 & & & & \\
\hline $\mathrm{pN}$ & & & $<0.001$ & 1.434 & $1.117-1.840$ & 0.005 \\
\hline No & 137 & $57.3^{\mathrm{a}}$ & & & & \\
\hline N1 & 72 & 31.0 & & & & \\
\hline $\mathrm{N} 2$ & 50 & 24.0 & & & & \\
\hline $\mathrm{N} 3$ & 17 & 14.0 & & & & \\
\hline TNM stage & & & $<0.001$ & 1.201 & $0.856-1.685$ & 0.290 \\
\hline I & 22 & $64.1^{\mathrm{a}}$ & & & & \\
\hline II & 129 & 64.0 & & & & \\
\hline III & 125 & 24.0 & & & & \\
\hline Adjuvant therapy & & & 0.147 & & & \\
\hline No & 148 & 30.0 & & & & \\
\hline $\mathrm{RT}$ & 41 & 63.0 & & & & \\
\hline $\mathrm{CT}$ & 59 & 54.0 & & & & \\
\hline CRT & 28 & 30.0 & & & & \\
\hline STMN1 & & & $<0.001$ & 2.149 & $1.555-2.970$ & $<0.001$ \\
\hline Low & 184 & 64.0 & & & & \\
\hline High & 92 & 23.0 & & & & \\
\hline
\end{tabular}

${ }^{a}$ Median survival time. Ut, upper third of thoracic esophagus; Mt, middle third of thoracic esophagus; Lt, lower third of thoracic esophagus; EGJ, esophagogastric junction; MST, median survival time; RT, radiotherapy; CT, chemotherapy; CRT, chemoradiotherapy.

$13.1 \pm 4.2 \%$, which was lower than that noted in the control cells $(22.5 \pm 2.2 \%)$. However, the results did not achieve a significant difference $(\mathrm{P}>0.05)$.
Upregulation of STMN1 expression promotes the migration, invasion and proliferation of ESCC cells. Finally, we upregulated STMN1 expression to identify its function in cell 
Table III. Univariate and multivariate analyses of disease-free survival (DFS) on clinicopathological characteristics.

\begin{tabular}{|c|c|c|c|c|c|c|}
\hline \multirow{2}{*}{$\begin{array}{l}\text { Patient } \\
\text { characteristics }\end{array}$} & \multirow{2}{*}{$\begin{array}{l}\text { No. of } \\
\text { patients }^{\mathrm{a}}\end{array}$} & \multirow{2}{*}{$\begin{array}{c}\text { MST } \\
\text { (month) }\end{array}$} & \multirow{2}{*}{$\begin{array}{c}\text { Univariate } \\
\text { analysis }\end{array}$} & \multicolumn{3}{|c|}{ Multivariate analysis } \\
\hline & & & & HR & $95 \% \mathrm{CI}$ & P-value \\
\hline Gender & & & 0.736 & & & \\
\hline Male & 213 & 27.0 & & & & \\
\hline Female & 56 & 25.0 & & & & \\
\hline Age (years) & & & 0.124 & & & \\
\hline$\leq 55$ & 106 & 47.0 & & & & \\
\hline$>55$ & 163 & 23.0 & & & & \\
\hline Location & & & 0.242 & & & \\
\hline Ut & 17 & 20.0 & & & & \\
\hline Mt & 117 & 47.0 & & & & \\
\hline $\mathrm{Lt}$ & 135 & 23.0 & & & & \\
\hline Differentiation & & & 0.004 & 1.304 & $0.921-1.847$ & 0.135 \\
\hline G1 & 41 & 64.0 & & & & \\
\hline G2 & 208 & 28.0 & & & & \\
\hline G3 & 20 & 14.0 & & & & \\
\hline Length (cm) & & & 0.017 & 1.341 & $1.072-1.678$ & 0.010 \\
\hline$\leq 3$ & 59 & 62.0 & & & & \\
\hline $3-5$ & 129 & 23.0 & & & & \\
\hline$\geq 5$ & 79 & 17.0 & & & & \\
\hline $\mathrm{pT}^{\mathrm{b}}$ & & & 0.103 & & & \\
\hline $\mathrm{T} 1$ & 10 & & & & & \\
\hline $\mathrm{T} 2$ & 43 & & & & & \\
\hline $\mathrm{T} 3$ & 221 & & & & & \\
\hline $\mathrm{T} 4$ & 1 & & & & & \\
\hline pN & & & $<0.001$ & 1.385 & $1.081-1.775$ & 0.010 \\
\hline No & 133 & 81.0 & & & & \\
\hline N1 & 70 & 21.0 & & & & \\
\hline $\mathrm{N} 2$ & 49 & 16.0 & & & & \\
\hline N3 & 17 & 10.0 & & & & \\
\hline TNM stage & & & $<0.001$ & 1.149 & $0.743-1.778$ & 0.532 \\
\hline I & 20 & $63.4^{\mathrm{c}}$ & & & & \\
\hline II & 125 & 64.0 & & & & \\
\hline III & 124 & 17.0 & & & & \\
\hline Adjuvant therapy & & & 0.174 & & & \\
\hline No & 143 & 29.0 & & & & \\
\hline RT & 41 & 62.0 & & & & \\
\hline $\mathrm{CT}$ & 58 & 23.0 & & & & \\
\hline CRT & 27 & 22.0 & & & & \\
\hline STMN1 & & & $<0.001$ & 1.767 & $1.278-2.444$ & 0.001 \\
\hline Low & 177 & 62.0 & & & & \\
\hline High & 92 & 16.0 & & & & \\
\hline
\end{tabular}

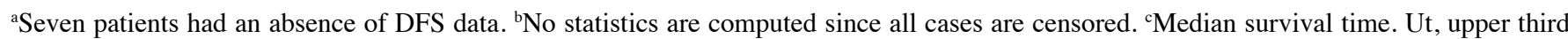
of thoracic esophagus; Mt, middle third of thoracic esophagus; Lt, lower third of thoracic esophagus; EGJ, esophagogastric junction; MST, median survival time; RT, radiotherapy; CT, chemotherapy; CRT, chemoradiotherapy.

motility and proliferation. Wound-healing assay (Fig. 5A) and migration assay (Fig. 5B) showed that overexpression of STMN1 significantly increased cell migration in both the
KYSE150 and KYSE450 cells. The same results were also observed in the invasion assay (Fig. 5B). Colony formation assay with STMN1 overexpression also showed a higher 

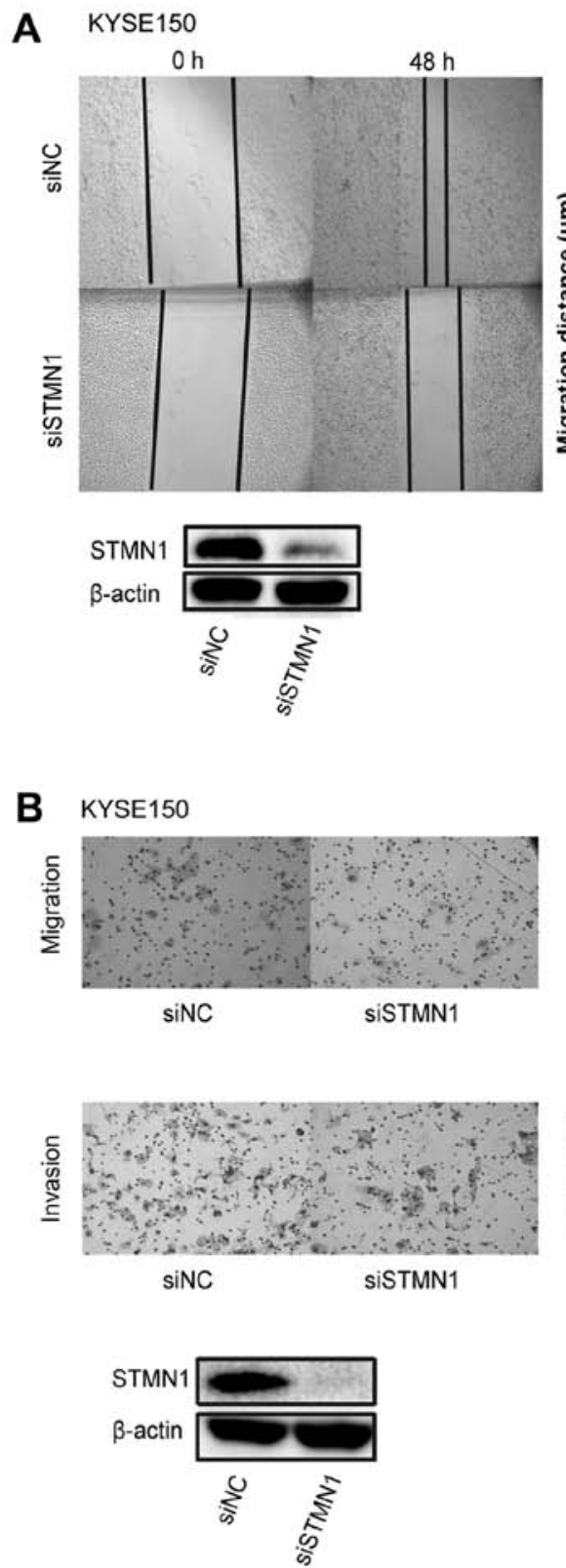

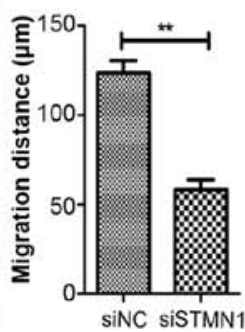

siNC siSTMN1
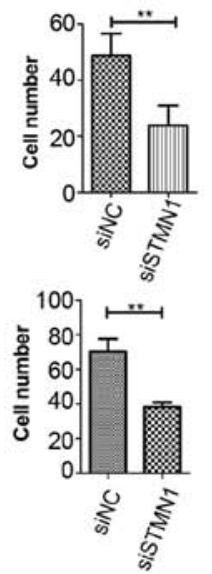

KYSE450
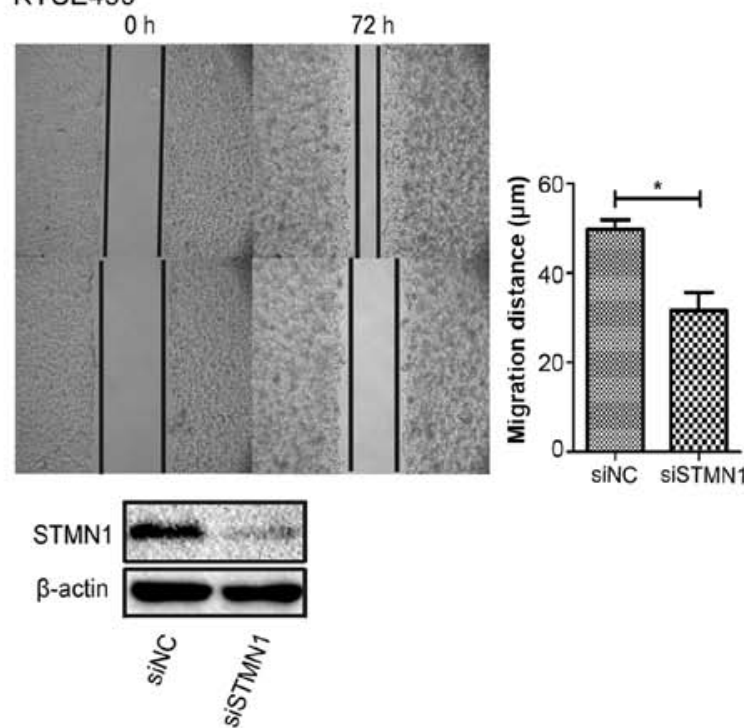

KYSE450

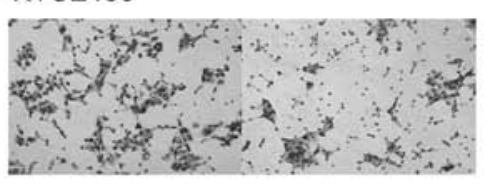

siSTMN1
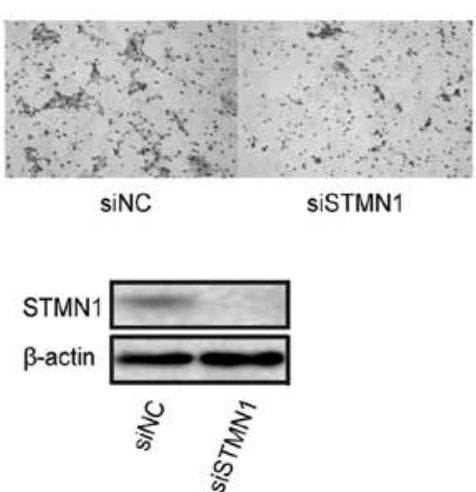
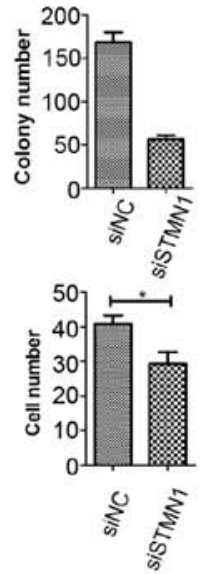

Figure 3. Knockdown of STMN1 inhibits the migration and invasion of oesophageal squamous cell carcinoma (ESCC) cells. (A) The wound-recovery result after knockdown in KYSE150 and KYSE450 cells, visualized under a microscope at a magnification of x40. (B) Knockdown of STMN1 inhibited cell migration and invasion by Transwell assays in the KYSE150 and KYSE450 cells. ${ }^{*} \mathrm{P}<0.05 ;{ }^{* *} \mathrm{P}<0.01$.

colony number (Fig. 5C). The results indicated that STMN1 overexpression promoted ESCC cell motility and proliferation.

\section{Discussion}

In the present study, we found that STMN1 overexpression indicated a poorer prognosis and the expression of STMN1 was correlated with tumour grade. In addition, according to the univariate and multivariate analyses, STMN1 expression was found to be an independent prognostic factor. KYSE150 and KYSE450 cells were used to investigate the biological function of STMN1 in ESCC. Knockdown of STMN1 expression inhibited the motility and invasion ability of the ESCC cells, as well as inhibited tumour cell proliferation and induced cell cycle arrest in the G1 phase. Upregulation of STMN1 expression promoted cell migration, invasion and proliferation.
In previous studies, STMN1 was reported to be highly expressed in many malignancies (7). The present study showed that overexpression of STMN1 indicated a poorer prognosis and was an independent prognostic factor for ESCC. Similar results were also reported in other malignancies, such as oral squamous cell carcinoma (11), breast (24), pancreatic (25) and gastric cancer (26), hepatoma (27) and ovarian carcinoma (8). We also found that the expression of STMN1 was correlated with tumour grade and a higher proportion of cells with STMN1 overexpression was found in cells with poor differentiation (Table I). STMN1 expression was closely related to the state of cell differentiation, not only in erythropoietic and neurite differentiation (28), but also in some malignant cells $(11,29-31)$. These results indicate that STMN1 expression is an important biomarker for ESCC. 

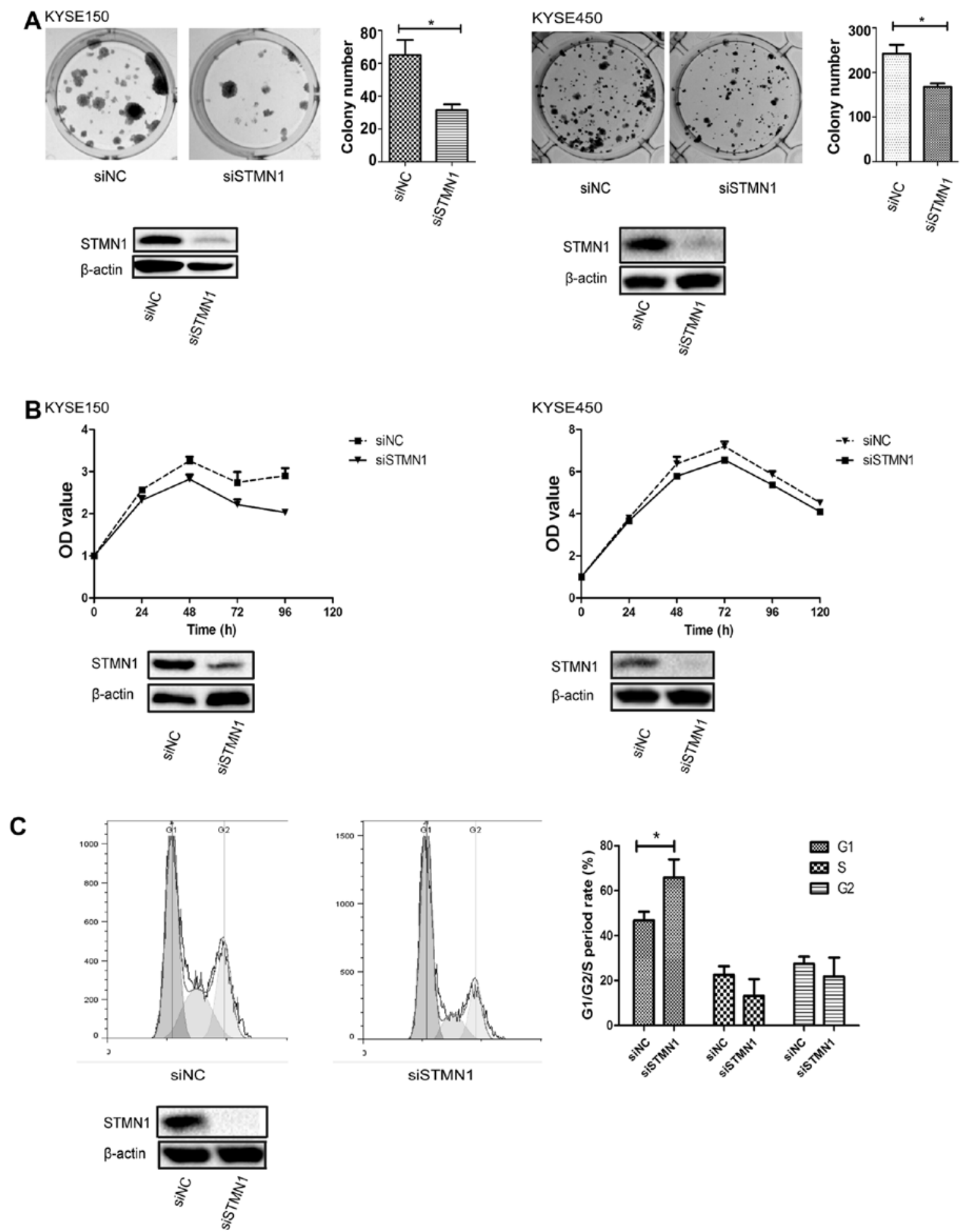

Figure 4. Knockdown of STMN1 inhibits proliferation and induces cell cycle arrest at the G1 phase of oesophageal squamous cell carcinoma (ESCC) cells. (A) Knockdown of STMN1 inhibited cell proliferation by colony formation assay in the KYSE150 and KYSE450 cells. (B) Knockdown of STMN1 inhibited cell proliferation by MTS assay in the KYSE150 and KYSE450 cells. (C) Cell cycle analysis by flow cytometry. ${ }^{*} \mathrm{P}<0.05$.

We also performed a series of assays to investigate further the biological function of STMN1 in ESCC cells. According to wound-healing, and Transwell migration and invasion assays, we found that the ability of cell migration and invasion was impaired by deficient STMN1 (Fig. 3). The same result was observed in the KYSE30 and KYSE410 cells. Similar results were reported by Liu et al (31) in ESCC, and also observed in other malignancies $(5,29)$. Moreover, the opposite phenomenon was presented after upregulating STMN1 expression (Fig. 5). These findings suggest that STMN1 may play a crucial role in the process of tumour metastasis by regulating microtubule dynamics. However, this mechanism needs to be further explored.

The regulation of microtubule depolymerization by STMN1 is essential in the cell cycle. STMN1 appears to be involved in the $\mathrm{G} 1 / \mathrm{S}$ and $\mathrm{G} 2 / \mathrm{M}$ checkpoints to regulate cell 
A KYSE150
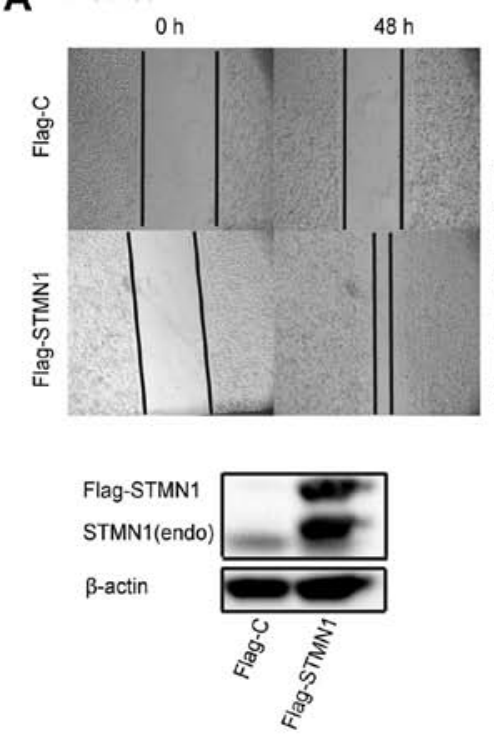

B KYSE150
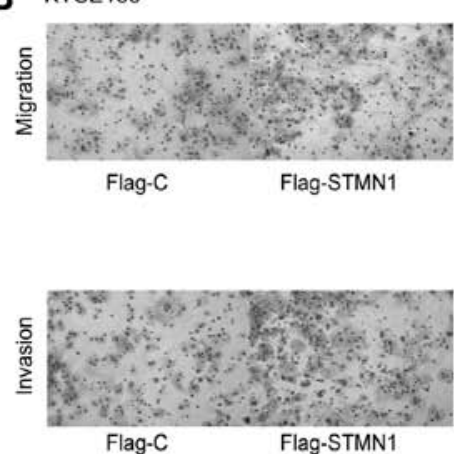

Flag-STMN1

STMN1(endo)

$\beta$-actin

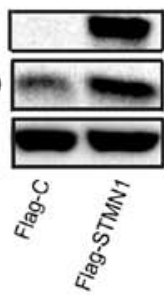

C

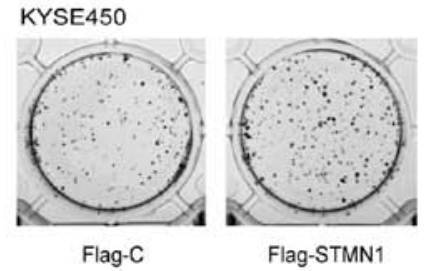

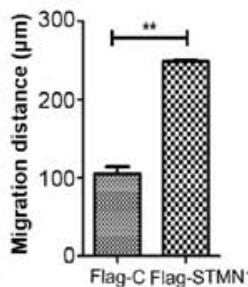

Flag-C Flag-STMN1
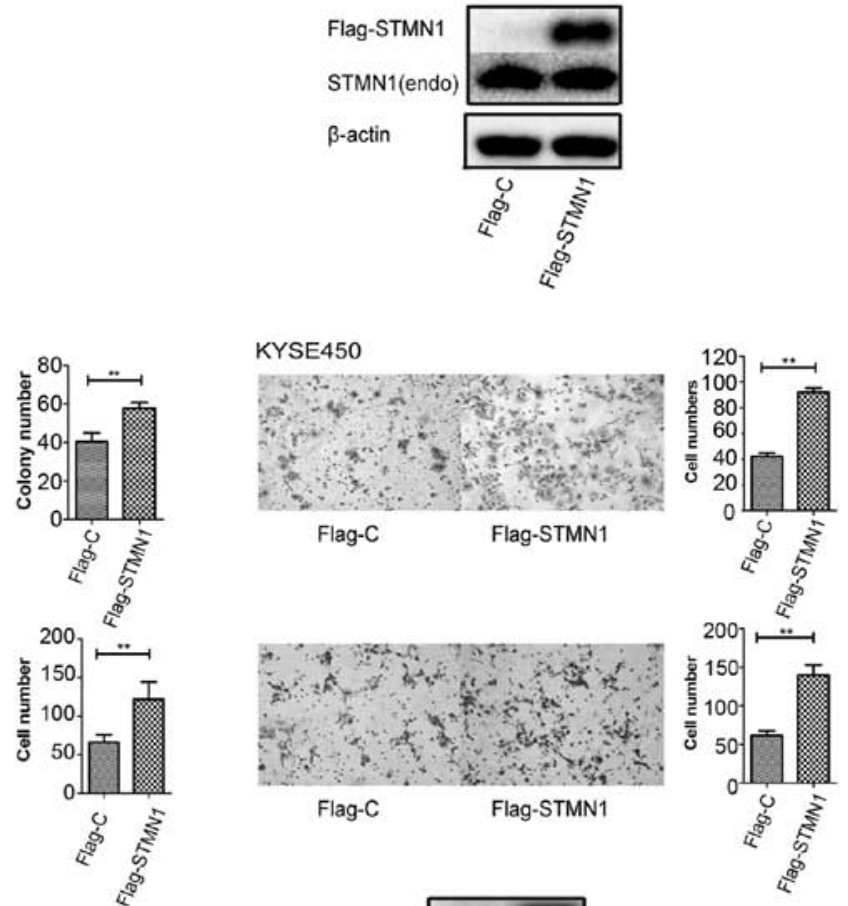

KYSE450
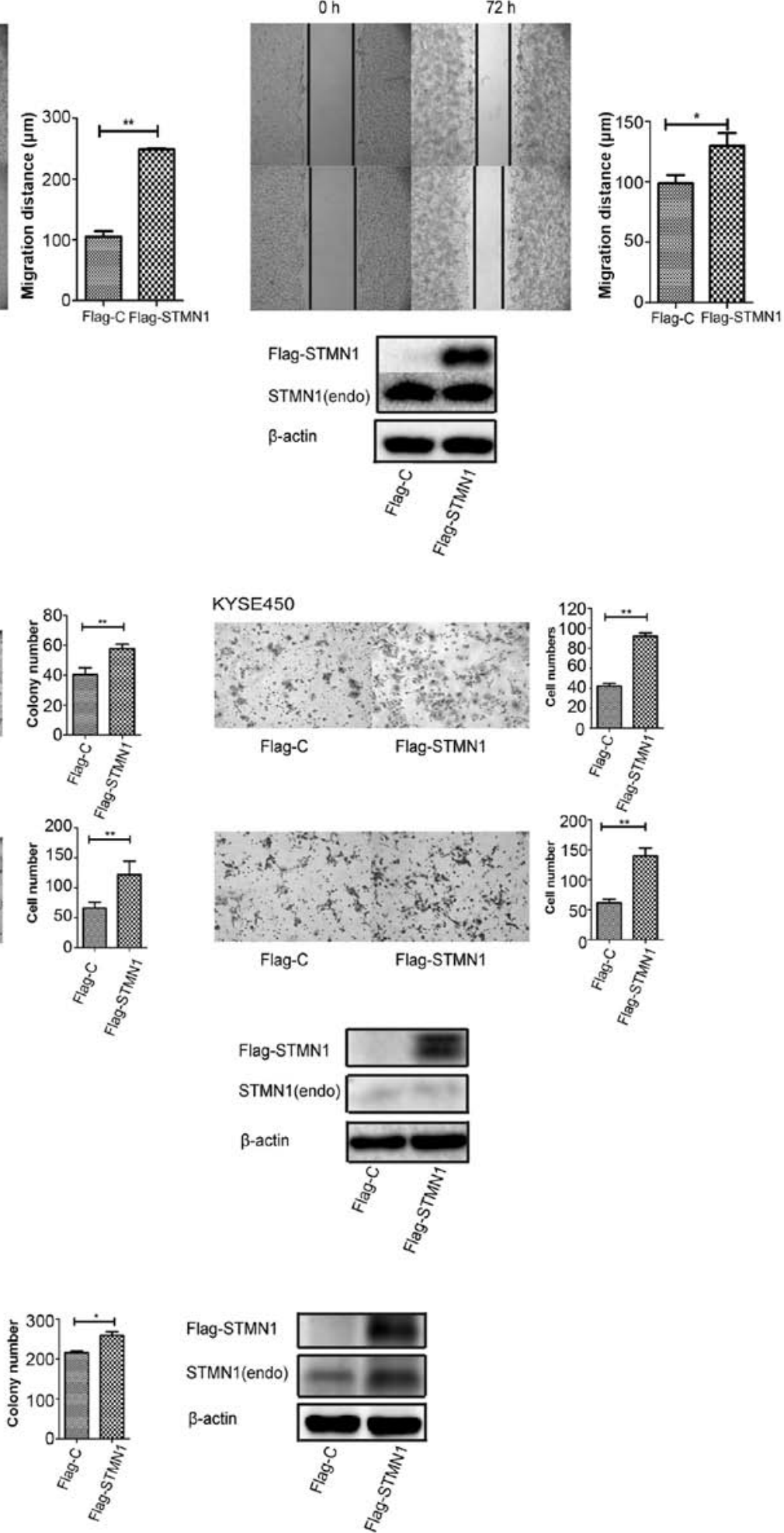

Figure 5. Upregulation of STMN1 promotes migration, invasion and proliferation of oesophageal squamous cell carcinoma (ESCC) cells. (A) The woundrecovery result after upregulation of STMN1 in the KYSE150 and KYSE450 cells. (B) Upregulation of STMN1 promoted cell migration and invasion in the KYSE150 and KYSE450 cells. (C) Upregulation of STMN1 promoted colony formation in the KYSE450 cells. ${ }^{*} \mathrm{P}<0.05 ;{ }^{* *} \mathrm{P}<0.01$.

cycle proliferation by interaction with other cell cycle control proteins such as p53 and $\mathrm{Rb}$ (28). Our results also support this idea; we found cell cycle arrest in the G1/S phase following the knockdown of STMN1 expression. The same results were also reported in hypopharyngeal squamous cell carcinoma by Chen et al (32).
A proliferation assessment was also performed using MTS agent and colony formation assay. A significantly decreased proliferative rate was shown in both KYSE150 and KYSE450 cells after STMN1 knockdown (Fig. 4). Our findings are consistent with previous studies in hepatoma (27) and cutaneous squamous cell carcinoma (29). In some solid tumours, 
such as breast and ovarian cancer, it was shown that tumours with high proliferative potential generally express higher levels of STMN1 than less proliferative tumours (4). These observations suggest a strong correlation between STMN1 expression and cellular proliferation in malignant cells.

STMN1 expression was significantly associated with prognosis and tumour differentiation in ESCC, indicating that STMN1 expression is an independent prognostic factor for ESCC and could be a potential biomarker of ESCC. Regulation of STMN1 expression could influence tumour cell motility, invasion, and proliferation. In conclusion, our data indicate that STMN1 plays an important role in cancer progression and may be a new therapeutic target for the treatment of ESCC.

\section{Acknowledgements}

The present study was supported by the National Natural Science Foundation of China (grant nos. 30770982, 81360331, 81472613 and 81572341), the Natural Science Foundation of China-Guangdong Joint Fund (grant nos. U1301227 and U0932001), and the Science and Technology Planning Project of Guang Dong Province (grant no. 2014A030304060), and the Department of Education, Guangdong Government under the Top-Tier University Development Scheme for Research and Control of Infectious Diseases.

\section{References}

1. Enzinger PC and Mayer RJ: Esophageal cancer. N Engl J Med 349: 2241-2252, 2003

2. Kollarova H, Machova L, Horakova D, Janoutova $G$ and Janout $V$ : Epidemiology of esophageal cancer - an overview article. Biomed Pap Med Fac Univ Palacky Olomouc Czech Repub 151: 17-20, 2007.

3. Pennathur A, Gibson MK, Jobe BA and Luketich JD: Oesophageal carcinoma. Lancet 381: 400-412, 2013.

4. Rubin CI and Atweh GF: The role of stathmin in the regulation of the cell cycle. J Cell Biochem 93: 242-250, 2004.

5. Tian FJ, Qin CM, Li XC, Wu F, Liu XR, Xu WM and Lin Y: Decreased stathmin-1 expression inhibits trophoblast proliferation and invasion and is associated with recurrent miscarriage. Am J Pathol 185: 2709-2721, 2015.

6. Machado-Neto JA, Saad STO and Traina F: Stathmin 1 in normal and malignant hematopoiesis. BMB Rep 47: 660-665, 2014.

7. Rana S, Maples PB, Senzer N and Nemunaitis J: Stathmin 1: A novel therapeutic target for anticancer activity. Expert Rev Anticancer Ther 8: 1461-1470, 2008.

8. Wei SH, Lin F, Wang X, Gao P and Zhang HZ: Prognostic significance of stathmin expression in correlation with metastasis and clinicopathological characteristics in human ovarian carcinoma Acta Histochem 110: 59-65, 2008.

9. Ghosh R, Gu G, Tillman E, Yuan J, Wang Y, Fazli L, Rennie PS and Kasper S: Increased expression and differential phosphorylation of stathmin may promote prostate cancer progression. Prostate 67: 1038-1052, 2007.

10. Baquero MT, Hanna JA, Neumeister V, Cheng H, Molinaro AM, Harris LN and Rimm DL: Stathmin expression and its relationship to microtubule-associated protein tau and outcome in breast cancer. Cancer 118: 4660-4669, 2012.

11. Ma HL, Jin SF, Tao WJ, Zhang ML and Zhang ZY: Overexpression of stathmin/oncoprotein 18 correlates with poorer prognosis and interacts with p53 in oral squamous cell carcinoma. J Craniomaxillofac Surg 44: 1725-1732, 2016.
12. Gan L, Guo K, Li Y, Kang X, Sun L, Shu H and Liu Y: Upregulated expression of stathmin may be associated with hepatocarcinogenesis. Oncol Rep 23: 1037-1043, 2010.

13. Zhang HZ, Gao P, Yan L and Lin F: Significance of stathmin gene overexpression in osteosarcoma cells. Ai Zheng 23: 493-496, 2004 (In Chinese).

14. Sun R, Liu Z, Wang L, Lv W, Liu J, Ding C, Yuan Y, Lei G and $\mathrm{Xu} C$ : Overexpression of stathmin is resistant to paclitaxel treatment in patients with non-small cell lung cancer. Tumour Biol 36: 7195-7204, 2015.

15. Nie W, Xu MD, Gan L, Huang H, Xiu Q and Li B: Overexpression of stathmin 1 is a poor prognostic biomarker in non-small cell lung cancer. Lab Invest 95: 56-64, 2015.

16. Wang F, Wang LX, He W, Zhu LN, Zhao PR, Fan QX: Expression of stathmin in esophageal squamous cell carcinoma and its biological significance. Nan Fang Yi Ke Da Xue Xue Bao 30: 1552-1557, 2010 (In Chinese).

17. Akhtar J, Wang Z, Jiang WP, Bi MM and Zhang ZP: Stathmin overexpression identifies high risk for lymphatic metastatic recurrence in $p \mathrm{~N}_{0}$ esophageal squamous cell carcinoma patients. J Gastroenterol Hepatol 29: 944-950, 2014.

18. Rice TW, Blackstone EH and Rusch VW: 7th edition of the AJCC Cancer Staging Manual: Esophagus and esophagogastric junction. Ann Surg Oncol 17: 1721-1724, 2010.

19. Fléjou JF: WHO Classification of Digestive Tumors: 4th edition. Ann Pathol 31 (Suppl 5): S27-S31, 2011 (In French).

20. Xie JJ, Xu LY, Wu ZY, Zhao Q, Xu XE, Wu JY, Huang Q and Li EM: Prognostic implication of ezrin expression in esophageal squamous cell carcinoma. J Surg Oncol 104: 538-543, 2011.

21. Sun LL, Holowatyj A, Xu XE, Wu JY, Wu ZY, Shen JH, Wang SH, Li EM, Yang ZQ and Xu LY: Histone demethylase GASC1, a potential prognostic and predictive marker in esophageal squamous cell carcinoma. Am J Cancer Res 3: 509-517, 2013.

22. Xie JJ, Zhang FR, Tao LH, Lü Z, Xu XE, Jian S, Xu LY and Li EM: Expression of ezrin in human embryonic, fetal, and normal adult tissues. J Histochem Cytochem 59: 1001-1008, 2011.

23. Xie JJ, Xu LY, Wu JY, Shen ZY, Zhao Q, Du ZP, Lv Z, Gu W, Pan F, Xu XE, et al: Involvement of CYR61 and CTGF in the fascin-mediated proliferation and invasiveness of esophageal squamous cell carcinomas cells. Am J Pathol 176: 939-951, 2010.

24. Kuang XY, Chen L, Zhang ZJ, Liu YR, Zheng YZ, Ling H, Qiao F, Li S, Hu X and Shao ZM: Stathmin and phospho-stathmin protein signature is associated with survival outcomes of breast cancer patients. Oncotarget 6: 22227-22238, 2015.

25. Lu Y, Liu C, Cheng H, Xu Y, Jiang J, Xu J, Long J, Liu L and Yu X: Stathmin, interacting with Nf- $\kappa \mathrm{B}$, promotes tumor growth and predicts poor prognosis of pancreatic cancer. Curr Mol Med 14: 328-339, 2014.

26. Ke B, Wu LL, Liu N, Zhang RP, Wang CL and Liang H: Overexpression of stathmin 1 is associated with poor prognosis of patients with gastric cancer. Tumour Biol 34: 3137-3145, 2013.

27. Hsieh SY, Huang SF, Yu MC, Yeh TS, Chen TC, Lin YJ, Chang CJ, Sung CM, Lee YL and Hsu CY: Stathmin1 overexpression associated with polyploidy, tumor-cell invasion, early recurrence, and poor prognosis in human hepatoma. Mol Carcinog 49: 476-487, 2010.

28. Sherbet GV and Cajone F: Stathmin in cell proliferation and cancer progression. Cancer Genomics Proteomics 2: 227-237, 2005.

29. Li X, Wang L, Li T, You B, Shan Y, Shi S, Qian L and Cao X: STMN1 overexpression correlates with biological behavior in human cutaneous squamous cell carcinoma. Pathol Res Pract 211: 816-823, 2015.

30. Li J, Hu G, Kong F, Wu K, Song K, He J and Sun W: Elevated STMN1 expression correlates with poor prognosis in patients with pancreatic ductal adenocarcinoma. Pathol Oncol Res 21: 1013-1020, 2015.

31. Liu F, Sun YL, Xu Y, Liu F, Wang LS and Zhao XH: Expression and phosphorylation of stathmin correlate with cell migration in esophageal squamous cell carcinoma. Oncol Rep 29: 419-424, 2013.

32. Chen Y, Zhang Q, Ding C, Zhang X, Qiu X and Zhang Z: Stathmin 1 overexpression in hypopharyngeal squamous cell carcinoma: A new promoter in FaDu cell proliferation and migration. Int J Oncol 50: 31-40, 2017. 